\title{
Distance Teaching in Chemistry: Opportunities and Limitations
}

\author{
Véronique Breguet Mercier, Ulrich Scholten, Richard Baltensperger, Ludovic Gremaud, \\ and Michal Dabros
}

\begin{abstract}
Remote teaching in the tertiary education sector is a relatively common practice, and the implementation of digital solutions in chemistry teaching offers many new opportunities and tools. A survey was conducted after 3 months of emergency remote teaching linked to the COVID-19 pandemic and showed that half of the students estimated it was difficult to study remotely, and reported they had to invest more time compared to classroom teaching, which led to a drop in motivation. Professors also noted that the time necessary to invest in order to produce digital teaching content was enormous. Massive open online laboratories (MOOLs) and process simulators are interesting tools, but practical lab work and related know-how cannot fully be replaced by digital techniques. Finally, it appeared that the professor-student interaction is very important in the distance-learning process, and that a high level of pedagogical (inter)activity is mandatory to maintain motivation and better quality of teaching and learning.
\end{abstract}

Keywords: Digital teaching · Distance teaching · Emergency remote teaching · Pedagogic innovation

Véronique Breguet Mercier studied in chemical engineering, followed by a $\mathrm{PhD}$ in the Laboratory Biological and Chemical Engineering at EPFL. She then joined Syngenta in Monthey, as Process Engineer for Development and Production. After 8 years in industry, she decided to move to the School of Engineering and Architecture Fribourg (HEIA-FR) as a Professor of Industrial Chemistry and Bioprocesses with a strong interest in Pedagogic Innovation.

\section{Context and Introduction}

Over the past few months, remote teaching in the tertiary sector has become a common practice. In this paper, our intent is to share with other colleagues our experience of remote teaching in the field of chemistry. It is important to state that our article reflects a special situation where distance education was suddenly imposed due to the partial confinement that occurred during the initial wave of the COVID-19 pandemic in Switzerland (from mid-March to June, 2020). This mode of teaching is sometimes qualified as 'Emergency Remote Teaching' (ERT). ${ }^{[1]}$ The purpose of this article is to discuss the different opportunities and limitations that might arise in theoretical and practical teaching of chemistry at the Bachelor and Master levels. Theoretical approaches to digital teaching and associated link to ERT will be addressed. A survey of professors and students that was conducted after ERT was implemented evaluated our institution perception compared to previous concepts. Finally, good practices and tools will be proposed to help teachers with distance teaching.

\section{Digital Teaching}

The act of teaching can be represented by a triangle ${ }^{[2]}$ where each angle represents the different participants involved in the pedagogical activity: the teacher, the student, and the knowledge. Each edge of the triangle connects the three participants mentioned previously to the implemented processes (Fig. 1). The teacher and the student are connected through interaction; the teacher and the knowledge are connected through teaching (the teaching process); finally, the knowledge and the student are joined through learning. In education, these three processes happen simultaneously, even though the intensity of each might differ. Consequently, a pedagogical sequence is a trajectory of a point moving within the triangle as a function of the evolution of the educational situation.

The implementation of digital techniques for teaching modifies the triangle, since a new factor is now present, transforming the pedagogical triangle into a tetrahedron. ${ }^{[3,4]}$ Thus, the number of edges is increased from 3 to 6, entailing new interactions between the digital techniques and other participants (Fig 1): The knowledge and the digital techniques are connected through digitalization; the student and the digital techniques are joined through enhancement and finally the teacher and the digital techniques are connected via potentiation. Based on this representation, the pedagogical sequence is now a journey within a three-dimensional system, offering new opportunities, but also sometimes distraction factors and technical issues. The addition of the digital component during lessons strongly modifies the interaction between students and professors, providing more freedom and independence to the learner, but also (often) higher responsibility requirement in their own learning.

Based on this tetrahedron representation, a list of success factors and potential errors during remote teaching can be identified as follows:

- Teaching edge: First, formulate measurable objectives adapted to current situation. Then plan and lay out different activities for your students. Due to distance, you must ensure that the proposed work is clear, precise and unambiguous, since misunderstanding may have consequences on learning and lead to a decrease in the motivation of the student.

- Learning edge: Distance teaching should catalyze selflearning, and the difficulty of proposed activities should be gradually increased. It is also important to provide solutions to exercises in order to provide a reassured feeling to the stu- 
Fig. 1. Representation of teaching (left) and teaching with the addition of digital techniques (right).
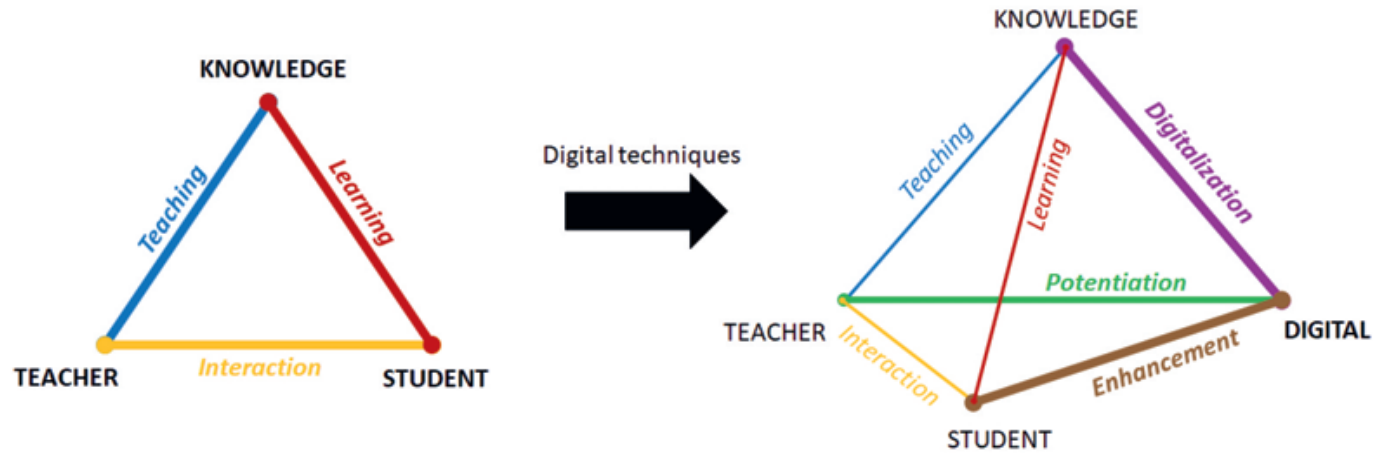

dents. Propose regular practices (and not graded evaluations) so that the candidate can evaluate his/her level.

- Interaction edge: During remote teaching, the teacher must maintain a presence and a relationship with the class, while organizing regular interactions. This can be achieved, for instance, by preparing a short introduction video, and organizing regular videoconferences with the whole class, a small group of students, or individual students. The teacher has to adopt the role of a coach and support the learners.

- Digitalization edge: In the numerical era, the amount of digital content and sources is huge, and has to be tackled with a critical perspective. As a coach, strive to develop the critical thinking capabilities of your students regarding the course subject. To help the information transmission, adapt your teaching material to short and synthetic elements. Do not hesitate to fractionate the course chapters into smaller parts and to complete them with diversified complementary resources and activities.

- Enhancement edge: Remote studying with digital content is an opportunity to develop new skills, but also to encounter new difficulties related to the organization of work, memorization, and the assimilation of new learning methods. As a teacher, use all the communication opportunities to support and encourage the candidates to experiment with these new ways of working. Implement regular videoconferences, create and animate forums, encourage the class to collaborate while working in small groups.

- Potentiation edge: Professors starting digital teaching should increase their course content gradually, according to their digital competences, as well as those of their students, and as a function of the technological solutions available at their institution. The mode of content sharing, i.e. a synchronous or asynchronous mode needs to be considered regarding the autonomy of the students facing the required task. To keep them motivated and attentive, vary the format (video, voice commented slide show, audio tracks, collaborative readings, surveys, etc.) and ensure the topic is understood by organizing quizzes to assess the level of knowledge.

\section{Methods and Pedagogical Approaches for Remote Teaching}

There are numerous possibilities to teach with digital solutions, such as synchronous/asynchronous methods, presence and distance learning, hybrid teaching, bimodal teaching and so on. During the COVID-19 lockdown, the sudden change of method resulted in an Emergency Remote Teaching (ERT) setting. This situation led to many disadvantages such as: lack of socialization between the students, loss of motivation, student dropout, unequal opportunities of success regarding social classes, etc.

To go live with this 'Emergency' situation during remote teaching, it is advised to anticipate and choose the appropriate teaching methods. The choice of the right pedagogical method to apply is dependent on two main factors: ${ }^{[1]}$
- The proportion of synchronous versus asynchronous teaching (synchronism)

- The proportion of presence versus distance teaching (presentiality)

Synchronism is defined as the relative part of the teaching time that simultaneously engages teachers and students, wherever they are located. Presentiality represents either the proportion of the overall teaching time where the whole class is present in the institution/classroom/laboratory/auditorium (called time mode) or the fraction of the students allowed to enter the classroom for a given lesson (called number mode). The time mode is usually a factor of choice, whereas the number mode results from the educational system constraints such as a pandemic situation or building renovation, for instance. For both time and number modes the different pedagogical methods can be represented on a two-dimensional chart, as a function of synchronism and presentiality (Fig. 2).

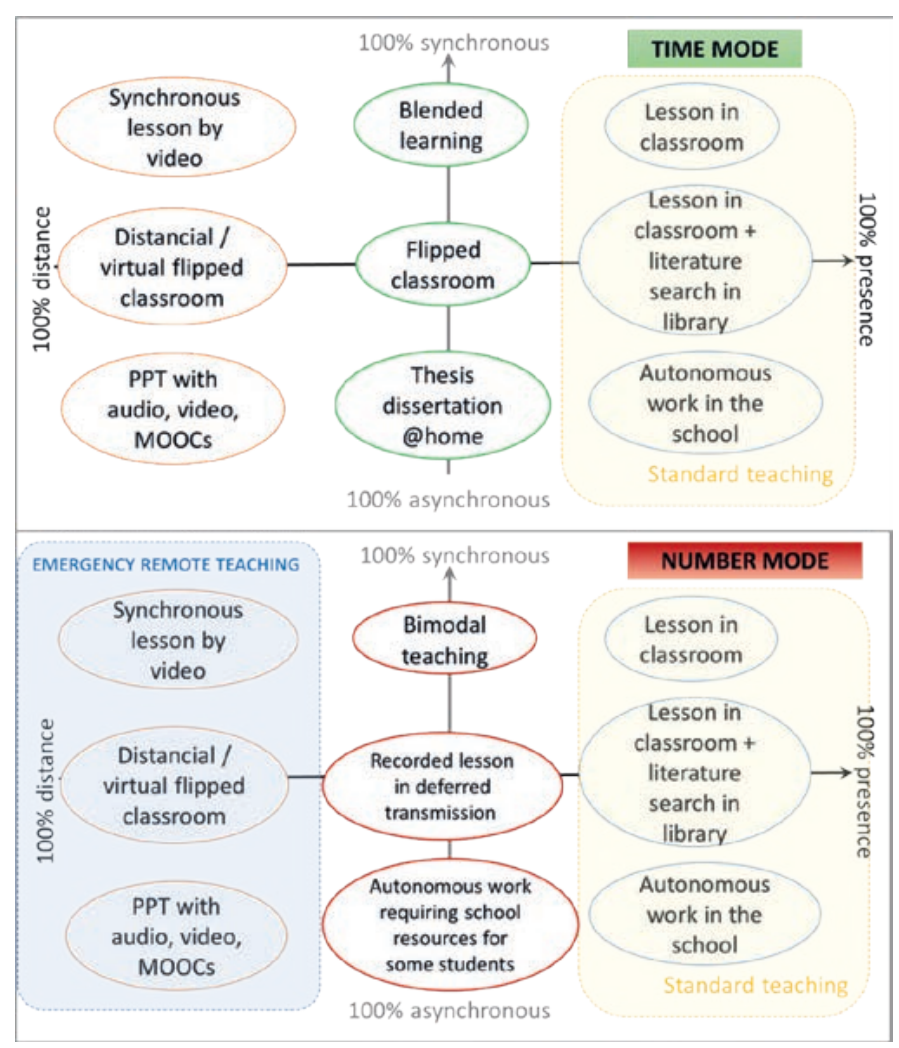

Fig. 2. Time-mode (up) and number mode (down) charts representing the different teaching methods as function of synchronism and presentiality. Right side shows available teaching methods during standard teaching within schools/universities, left side shows available teaching methods during ERT. The horizontal axis represents the presentiality axis while the vertical axis represents the synchronism axis. 
On such plots, conventional teaching is normally situated on the right-hand side (high proportion of presentiality), whereas Emergency Remote Teaching is on the left (no students in the class, or no teaching activities within the institution). During a pandemic, the following three categories of available methods can be identified for teaching:

- Synchronous teaching with whole class using video telecommunication tools (such as Microsoft Teams, Zoom, Skype)

- Distance flipped classroom (student self-study followed by synchronous videoconferencing)

- Asynchronous teaching, where supporting material is provided to the students for self-study (Massive Open Online Course/Lab (MOOC or MOOL), sound-enhanced slideshow, video capsules, book chapter reading, exercises provided with solutions, auto-corrected quizzes...)

When comparing number and time modes in Fig. 2, one can observe that teaching methods are the same for full presentiality and a full distance situation. The methods only differ for 'partial' presence, as it is listed on the vertical axis of each plot in Fig. 2.

The number of available methods for teaching in an ERT situation seems to be very limited: synchronous video lessons, virtual flipped classroom and recorded presentations/videos/MOOCS. However, the representations in Fig. 2 do not consider the creativity of the instructor, nor the degree of activity imposed on the students, an aspect which can be added as a third axis (see Fig. 3).

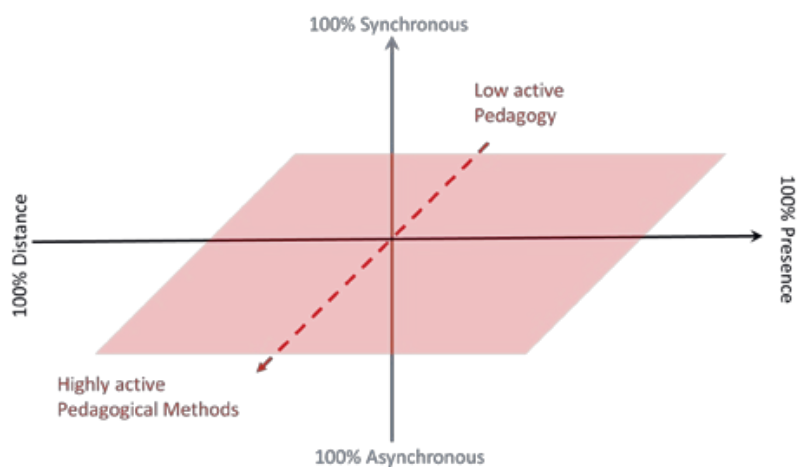

Fig. 3. 3D representation of pedagogical methods considering the level of activity of involved students

Choosing a technique that keeps students active during an ERT period is certainly a key of success to generate motivation and reduce student dropout. For instance, instead of simply showing a sound-enhanced or recorded slide show, it is easy to add interaction by asking the students questions (the Playposit platform https://go.playposit.com/ or H5P tool in Moodle can be used to add questions within a video). Another interesting tool for common readings is a Perusall e-reader platform (https://perusall.com/), where students can interact together while reading documents. During synchronous online teaching, survey applica-

Table 1. Pedagogical methods for distance teaching to enhance students activity levels

\section{Method Name}

Learning to learn

Seamless learning

Flipped learning

Teach back

Making thinking
visible

Evaluating

information

Personal inquiry learning

Science in remote lab

Maker culture

MOOC

\section{Principle}

Learning how to become an effective learner

Connecting learning across settings, technologies and activities

Blending teacher lesson and independent learning

Learning by what we have been taught

Opening windows into student learning and understanding

Deciding which source to trust

Learning through collaborative inquiry and active investigation

Guided experiments on authentic scientific equipment

Learning by making

Online resource for learning

\section{Explanation}

Studying at distance implies more responsibility lies on the student. Learning to learn involves being able to: decide what you need and help you to learn, set goals, find valuable resources, choose learning strategies, reflect on progress, develop creative skills and evaluate learning outcomes.

This method brings together learning taking place at different locations and times. Starts with and activity led by a teacher, and moving into discussion with other online students, or friends, or family, etc. It can also happen 'accidentally' when information from TV or internet sparks discussion. Learners collect and link those experiences using a paper notebook.

At home, students watch videos, read books, etc. at their own pace. There is then time during live session with the teacher for activities encouraging students to think critically and tackle exercises.

The teacher explains something to the students. The learner tries to teach his new understanding back to the teacher (or another student, 'peer-to-peer' teaching). If necessary, the teacher clarifies the explanation.

Learning become effective when students can visualize their thinking (setting goals, assumption, concepts, strategies, ...) and can write/draw them onto paper.

Develops skills in evaluating information from different sources help learners to avoid fake news and misleading information.

Active exploration of questions of interest for which the student doesn't already have an answer. First refine the question with the teacher, and collect answers, compare and discuss with others.

Lab experiences enable students to experiment with material world (or virtually with data from it) to understand their concepts. Provides opportunity to focus more on learning goals than on handling apparatus.

Encourages people to learn by constructing/creating items. It emphasizes on experimenting and testing theories by making.

Open access online courses freely available online, with no limit regarding the class size. Most include a short video, sometimes also texts and quiz. 
tions such as Socrative (https://www.socrative.com/) or Woodclap (https://www.wooclap.com/fr/) can be used to engage students in the course and to evaluate their understanding.

Table 1 suggests different methodologies of increasing the level of activity for students, regarding the three categories of pedagogic methods available during an ERT situation. The Table is inspired by 'Teaching at a distance: methods that works', ${ }^{[5]}$ providing an extremely useful set of instructions and useful links for easily implementing those methods during distance lessons.

\section{Remote Teaching Survey during the COVID-19 Semi-Confinement}

In addition to developing the theoretical and practical considerations relative to remote and digital teaching, it was decided to monitor our professors' and students' perception of ERT during the COVID-19 pandemic through a survey. After three months of distance lessons (from mid-March until mid-June 2020), a survey was sent out to professors (20) and students (90) in the Chemistry department of the School of Engineering and Architecture of Fribourg, at both the Bachelor and Master levels. Within our institution in a normal situation, lessons are taught in classes that include between 15 and 35 students. This was also the case during ERT. The objective was to evaluate what was considered as potential factors limiting or enhancing teaching or learning for each group (students and teachers). The electronic questionnaire (drafted in Microsoft Forms) was structured as follows:

- Technical organization and course of lessons

- Teaching mode and method

- Tools used for teaching and evaluating

- How distance teaching was perceived, i.e. what are the advantages/disadvantages compared to the presential mode?

This survey was performed before the exam session, in order to avoid a possible distortion of results due to the upcoming assessments and summer exam session.

\subsection{Students' Point of View}

The questionnaire was built on 26 affirmations allowing the following answers 'I agree' (score $=4$ ) / 'I partially agree' (score $=3$ ) / 'I partially disagree' ( score $=2$ ) / 'I disagree' (score $=1$ ) and a neutral answer 'I don't know' (score $=0$ ). It was followed by two open questions, one of which asked the students to share their point of view regarding the potential and limitations of distance teaching, and one requesting an overall evaluation (of the quality) of the distance teaching during the last three months (with a maximum mark of 4).

The percentage of students who participated in the questionnaire was $81 \%$, allowing us to consider the answers as representative of the students' point of view. Regarding the first three points of the survey, their answers are summarized in Figs 4 and 5.

The principal challenge, cited by more than $60 \%$ of the students, was the lack of motivation. It was reported to be caused by multiple distraction sources (email, roommate or family, social networks, phone, TV, ...) and the difficulty of facing a computer screen over long periods of time. Moreover, half of them also complained about physical troubles or loneliness. Only half of the students stated that digital teaching was interesting, and one third mentioned it was difficult to interact (ask questions, get answers) with professors and classmates during lessons. Half of our students estimated that it was more difficult to study with distance learning and $60 \%$ had the impression they had to invest more time compared to frontal teaching.

On the positive side, the main cited advantages were the time saved in travel, the opportunity to have a more flexible time organization and the possibility to work at their own pace since recorded lessons could be watched again as many times as necessary. Finally, the average rating of the ERT during the three-month period was 2.95 out of 4 , showing the students were relatively satisfied with the adopted teaching approach.

\subsection{Professors' Point of View}

The professors' questionnaire was very similar to the students' one, allowing some extra open comments, especially regarding the tools and practices used during ERT. Almost all professors $(95 \%)$ took part to the survey, providing interesting answers, as summarized in Figs 4 and 5.

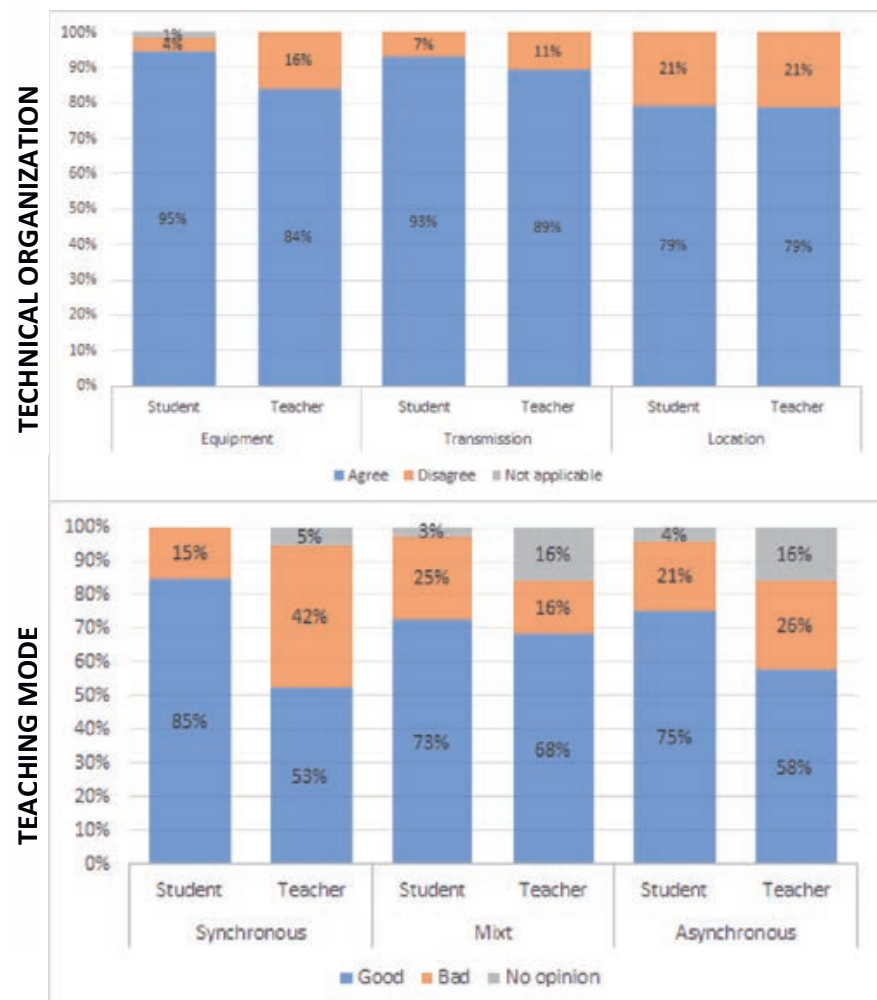

Fig. 4. Answers from students and teachers to the survey: Upper chart technical, transmission and location organization, lower chart comparison of teaching mode evaluation

The main disadvantage encountered by all professors was the workload and stress induced by the sudden ERT. Problems with motivation were reported less frequently than for the students, but the difficulties linked to distraction sources (email, family, social networks, phone, $\mathrm{TV}, . .$. ) and facing the computer screen all day were similar. More than half of the teachers also stated that interaction with students was more difficult than during presential teaching. 50\% affirmed that digital teaching was interesting. Overall, the professors rated the quality of their teaching experience with a mark of 2.58/4, which was lower than the grade provided by the students. The main advantages cited were the time saved in travel, and the opportunity to discover new ways of teaching, involving the students more in their own learning process.

\section{Tools to Overcome Limitation while Teaching Chemistry}

The main two limitations encountered during ERT were: finding alternative solutions for practical teaching in the labs, and summative tests and exams. Our institution strategy recommended to postpone lab work to summer, and to perform distance summative assessment only if possible, without major change to the initial plans (otherwise assessment will be planned at the end of ERT in presential mode). Regarding the assessment part, the survey ( $c f$. Section 4.) showed that only $32 \%$ of teachers within our school performed distance summative assessments during ERT last spring. 


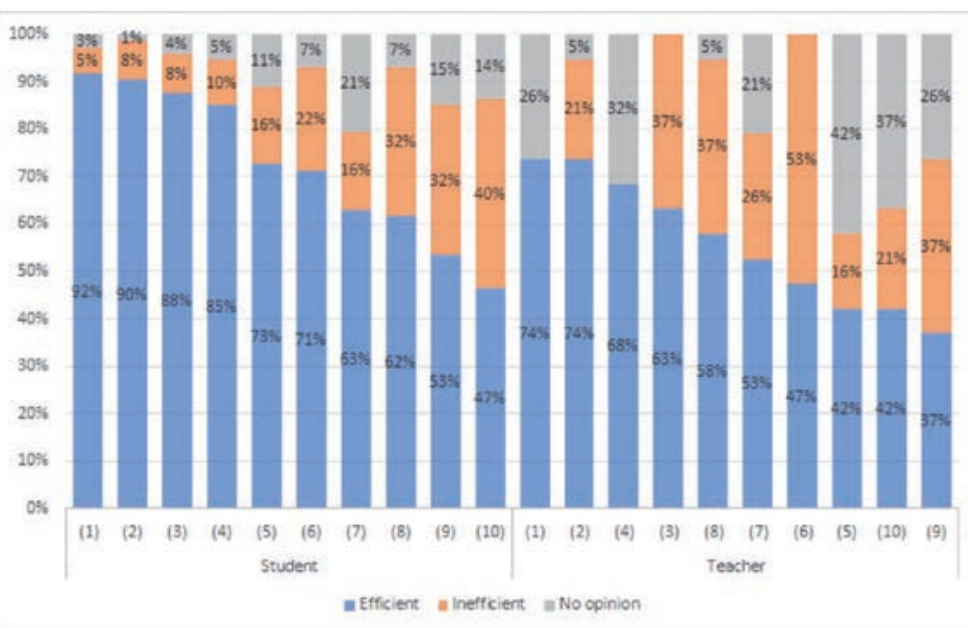

Fig. 5. Students and teachers evaluation regarding distance teaching

(1) Course material with audio comments

(2) Videoconference sessions for discussion, questions and exercises (Microsoft Teams, Zoom, etc.)

(3) Original and uncommented professor course support (powerpoint, pdf, etc...)

(4) Video capsules

(5) Practice quizzes (on Moodle, MS Forms...) (6) Full course references (textbook, handout...) (7) Practice tests (no mark)

(8) Individual mail exchange with professor (9) Forum of discussion

(10) Group work (projects, case studies....) tools efficiency.
Most of them chose the distance oral examination method to assess students' learnings, and only few of them proposed takehome projects to be realized remotely.

During the second wave of ERT in November 2020, lessons were learned from the previous situation: currently lab work and assessment are allowed in presential mode with adequate sanitary measures.

\subsection{Alternatives to Practical Lab Work}

In the field of chemistry, hands-on experience in running reactions and operating equipment is an indispensable step in the learning process. However, there are limitations to the amount of time students can spend doing practical work, a situation that has been exacerbated with the COVID-19 restrictions.

Nevertheless, some alternative or complementary activities can be offered, for instance reaction and process simulation software or MOOLs (massive open online laboratories). The concept of MOOLs is relatively recent and has been inspired by the success of massive open online courses (MOOCs). Online laboratories provide students with the opportunity to experiment remotely with various laboratories or pilot-plant equipment (or virtually with data from it) in order to gain basic understanding of the theoretical and practical concepts involved. A project, funded by the HES-SO and carried out by two partner schools (HES-SO Valais and the School of Engineering and Architecture Fribourg) is currently in progress with the aim to create and assess a series of MOOLs, two of which directly relate to the field of chemistry. One experiment involves pressure control inside a reaction vessel, while the other aims to characterize the hydrodynamics of a fluidized bed reactor. Benefits of online labs include flexibility of access, cost reduction and providing instantaneous results. Remote labs allow students the opportunity to experiment in virtually 'dangerous' situations without undergoing the consequences in case of a mistake. However, the practical skills involved with manipulating laboratory equipment are not possible to train.

Simulation software can assist to a large degree in the distance learning process. Appropriate implementation of these tools can support both theoretical and practical learning, enabling students to explore and reinforce their understanding of the interaction of physico-chemical parameters in a safe environment. With many organizations recruiting with a 'digital-first' mind-set, these skills are already considered as key competence for the future of the industry. At the HEIA-FR, Dynochem ${ }^{\circledR}$ and Reaction $\mathrm{Lab}^{\mathrm{TM}}$ (www.scale-up.com) are software integrated in the Bachelor and Master programs. With tools that are widely deployed in the pharmaceutical and agrochemical industries, students can follow some case studies from scientists working in leading companies.
For lecturers, a key element in the rapid integration of these tools into their curriculum is the availability of the off-the-shelf self-paced training material covering reactions, as well as common chemical unit operations such as mixing, heat transfer, distillation, crystallization (see Fig. 5), filtration and drying. This enables the lecturer to select the modules that are most suited to their subject and the student to work at his or her own pace, without the requirement of 'over-the-shoulder' instruction from the tutor. Moreover, an optional certification program also enables students to push themselves to add an extra achievement on their resume in view of the next step in their career.

\subsection{Students Assessments and Exams}

Take-home exams can be an effective tool for assessing students' learning, but also present some challenges in ensuring equity for those taking them.

Oral examination can be easily organized through videoconferences. The main limitation is to ensure that the candidates do not benefit from any help, which is not visible on the screen (another person in the same room, or hidden books/sheet of papers, etc.). The use of open-ended questions or asking to discuss and argue on a defined topic are interesting alternatives to prevent potential misbehavior.

For 'written' assessments, this kind of exam requires students to complete a task and submit their work within a strict time limit, and while working at home. During this time, students can consult their own notes, course texts and other materials and sometimes open web access. Many sources ${ }^{[7-10]}$ suggest that take-home exams work best with open-ended questions, and in more advanced courses. methods of assessment can be various, for example multiple choice quiz, case studies, projects, dissertation, etc.

Take-home exams involve many challenges: students need to provide their own workspace and computer equipment, adequate support should be available (both technical, and for clarification in case of factual errors in questions, etc.) for the duration of the assessment, and risk of unauthorized collaboration between students. To ensure reliability, validity and fairness, questions should be designed to demand higher order activities from students and checked by colleagues for possible misinterpretation. Written instructions should be carefully prepared in order to minimize student stress and queries during the assessment period.

Another important question is how to limit possible misbehavior. Changing questions each year prevents previous cohorts of students from sharing their work. Alternating the order of questions in a quiz or proposing different versions of the same exam with different numerical values (or molecules) are possibilities that are easily implemented. Requiring students to work 
with a recent source, or with specific course content and activities, limits opportunities for finding pre-existing content and tasks can be linked to a previous completed assessment to prove authorship.

\section{Conclusions}

Even though remote teaching is becoming more common, the implementation of digital in learning is not an easy task for instructors or students. Even for the digital native people, the technical prerequisite to use those new teaching/learning tools is not an evidence, and the sudden change from presential to distance teaching during ERT was not an easy task. Moreover, most of the available methodology for distance teaching are based on digital solutions, which might be an issue in case of technical or transmission failure, especially when using a synchronous teaching mode.

This survey aims to demonstrate that the interaction between professors and student is largely mandatory in the learning process, and that purely asynchronous teaching with low level of pedagogical activity leads to low motivation. A large part of our students estimated that it was more difficult to study with distance learning and had the impression they had to invest more time compared to the frontal teaching mode. Moreover, all professors mentioned that the time investment to propose digital content was enormous.

The ERT also showed that distance assessment is difficult, especially in the written form. The evaluation mode requires adaptation, such as proposing projects, case studies, dissertation, open-ended questions, which is not always easy for every topic in chemistry.

In the field of chemistry there are tasks that cannot be replaced by digital alternatives, especially the laboratory practice and related know-how skills. Some alternatives such as MOOLs or simulation can nevertheless be proposed.

Based on previous considerations, digital and distance teaching are interesting complementary tools for teaching chemistry, but will never replace standard teaching in classrooms, nor practical work in laboratories.

\section{Acknowledgements}

Thanks to all our colleagues within the Chemistry department at HEIA-FR for sharing best teaching practices and useful tools: Professors C. Allemann, J-P. Bourgeois, P. Brodard, T. Chappuis, O. Mamula Steiner,
R. Marti, O. Nicolet, C. Portmann, O. Vorlet, and also E. Bourguet for good advice regarding Pedagogical Support.

The authors thank Scale-up Systems, and particularly Joe Hannon and Steve Crooper, for the technical support and for providing generously powerful case studies for Dynochem ${ }^{\circledR}$ and ReactionLab ${ }^{\mathrm{TM}}$ during the distance teaching period.

[1] R-E.Eastes, 'L'enseignement en Période de COVID : une typologie pour sortir de l'urgence', SADAP HES-SO, August 2020, available at https://www.youtube.com/watch?v=_ITt7jzOpmA\&feature=youtu.be (accessed 17.12.2020)

[2] J. Houssaye, 'Le Triangle pédagogique. Théorie et pratiques de l'éducation scolaire', Peter Lang, Bern, 2000.

[3] J. Pita, R-E. Eastes, A-D. Salamin, G. Eckert, 'Enseigner avec le numérique Repères théoriques', SADAP HES-SO, June 2020, available at https://www. hes-so.ch/data/documents/Enseignement-aide-memoire-Enseigneraveclenu merique-12062020-12379.pdf (accessed 17.12.2020).

[4] R-E. Eastes, G. Eckert, J. Pita, 'Enseigner à distance grâce au numérique : conseils pratiques, SADAP HES-SO', June 2020, available at https://www.hesso.ch/data/documents/Enseignement-aide-memoire-EnseignerADistanceNumerique-12062020-12380.pdf (accessed 17.12.2020).

[5] The Open University, 'Teaching at a distance: methods that work', https://iet.open.ac.uk/pages/teaching-at-a-distance (accessed 17.12.2020).

[6] Innovative Pedagogy Report $\mathbf{2 0 2 0}$ by the Open University, Dublin City University and National Institute for Digital Learning, available (8.12.2020) on https://iet.open.ac.uk/innovating-pedagogy

[7] Harvard University, The Office of Academic Integrity and Student Conduct, 'Take Home Exams: Tell It Like It Is', https://honor.fas.harvard.edu/takehome-exams-tell-it-it (accessed 17.12.2020).

[8] The London School of Economics and Political Sciences, Eden Center for Education Enhancement, Take Home Assessment, https://info.lse.ac.uk/ staff/divisions/Eden-Centre/Assessment-Toolkit/Assessment-conditions/ Take-home-assessment (accessed 17.12.2020).

[9] Cyberlearn: HES-SO e-learning center, https://cyberlearn.hes-so.ch/ (accessed 17.12.2020).

[10] A. Dumont, Nouvelles formes d'évaluations à distance, Pedagoscope (blog and postcasts about tertiary education) https://pedagoscope.ch/nouvellesformes-devaluation-a-distance/ (accessed 17.12.2020).

\section{License and Terms}

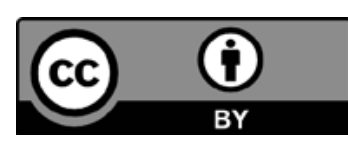

This is an Open Access article under the terms of the Creative Commons Attribution License CC BY 4.0. The material may not be used for commercial purposes.

The license is subject to the CHIMIA terms and conditions: (http:// chimia.ch/component/sppagebuilder/?view=page $\& i d=12$ ).

The definitive version of this article is the electronic one that can be found at https://doi.org/10.2533/chimia.2021.58 